\title{
O Gênero Negro Feminino nas Redes Sociais: o que Revelam as Produções Acadêmicas
}

\author{
Mory Márcia de Oliveira Loboํ, Cristiano Maciel ${ }^{1,2}$ \\ ${ }^{1}$ Programa de Pós-graduação em Educação \\ ${ }^{2}$ Instituto de Computação \\ Universidade Federal de Mato Grosso (UFMT) Cuiabá MT Brasil \\ caffenatasoul@gmail.com,cmaciel@ufmt
}

\begin{abstract}
The study's proposal is based on the central question: what is being produced on the theme of the black female gender, especially by black women on social networks? Considering the Brazilian context, this article presents a showcase of data, provided by the state of the art of scientific productions (dissertations and theses) related to the subject under examination.

Resumo: A proposta do estudo baseia-se na pergunta central: o que está sendo produzido sobre a temática do gênero feminino negro especialmente por mulheres negras em redes sociais? Considerando o contexto brasileiro, o presente artigo apresenta uma vitrine de dados, prestados pelo estado da arte de produções científicas (dissertações e teses) relacionadas ao tema ora em exame.
\end{abstract}

\section{1-Introdução}

O estudo sobre gênero feminino negro tem se intensificado em cenários e áreas em meio a enfrentamentos e resistências na luta por espaço e lugar de fala. Muitas iniciativas ocupam lugar central em trabalhos desenvolvidos intencionalmente desafiando as identidades sociais relacionadas a opressão, dominação e discriminação em áreas como na Computação e Tecnologias (LOBO; RIBEIRO; MACIEL, 2020).

A representação do gênero negro no ciberespaço instiga a refletir sobre a imagem estereotipada, aviltada, silenciada e relegada a um limbo epistemológico que sistematicamente, leva à perda de sua referência como ser humano principalmente no triste histórico da formação do pensamento racial no Brasil. Neusa Santos Souza (1983), psicanalista brasileira, em sua obra Torna-se Negro, alerta sobre os desdobramentos da ideologia do branqueamento que contribui para a falsa democracia racial, o narcisismo ideal, e o ideal do ego, presentes nas relações do negro com o branco, e a produção de conhecimentos de aquisição dominantes feitas para o negro com descarte de desvalorização.

Essas questões não estão alheias à realidade da mulher negra brasileira levando em consideração todo um histórico de racismo, sexismo, misoginia, em um campo de grandes contradições, padrões e regras impostas regadas à violência física, verbal e intelectual, questões que aparecem nos trabalhos analisados neste artigo via estado da arte. No espaço das redes sociais, a agenda do gênero negro, utilizando-se de linguagens e simbologias, alcança múltiplos internautas e se faz importante para o entendimento do que tem sido produzido neste campo.

Assim, a proposta deste trabalho limita-se a investigar pesquisas que tratem do gênero negro feminino no contexto das redes sociais, que escrevem sobre o tema em 
dissertações e teses. Por meio do estado da arte foram mapeados nove trabalhos, cujas abordagens teórico-metodológicas são analisadas, trazendo uma visão deste campo.

$\mathrm{O}$ artigo foi organizado com três subseções que melhor definem as estruturações da pesquisa e a discussão sobre redes sociais e gênero negro, bem como o resultado das análises dos trabalhos acadêmicos selecionados, tendo as considerações finais na quarta subseção.

\section{A pesquisa e seu caminho metodológico}

Nesta seção, apresenta-se o percurso metodológico e os resultados da pesquisa.

\subsection{Estado da arte}

O estado da arte toma como ponto central o mapeamento que empreende discussões sobre o campo acadêmico delineado e que gera um inventário descritivo das produções encontradas (THERRIEN NÓBREGA; THERRIEN, 2004, p.8). Nesse sentido, os autores enfatizam o caráter do cerne investigativo na relação entre o tema e o campo acadêmico.

Para a busca e seleção de dissertações e teses publicadas foram utilizadas cinco fontes, a saber: os anais da Biblioteca Digital Brasileira de Teses e Dissertações (BDTD), a literatura acadêmica do Google Acadêmico, os periódicos do Portal CAPES e os repositórios institucionais da Universidade Federal de Minas Gerais (UFMG) e da Universidade Federal Fluminense (UFF). Essas duas últimas bases foram consideradas, especialmente, por terem grupos que atuam neste campo. Os descritores utilizados para realização da busca foram: "mulheres negras, redes sociais", "feminismo negro em redes", "gênero negro em redes", "mulheres negras Youtubers" e "mulheres negras e Facebook". A busca retornou 40 trabalhos em um universo de 24 produções, foram excluídas aquelas que não correspondiam aos critérios estabelecidos, restando somente 09 assim distribuídas: dissertações (5) e teses (4).

A análise foi realizada buscando observar os seguintes questionamentos: Quais são os objetos de estudo das pesquisas desenvolvidas sobre gênero negro, mulheres e redes sociais? No corpus deste trabalho, destaca-se o levantamento dos seguintes critérios/procedimentos de seleção dos estudos: resumos, área de conhecimento, metodologia, ano, tipologia do estudo, leitura analítica, inferências e considerações, como o trabalho se enquadra na categoria pesquisada e se ele responde à problematização que foi proposta.

De forma geral, os trabalhos de pesquisa encontrados entre dissertações e teses desenvolvem análises em Ciências humanas destacando-se os seguintes totais de trabalho por área: Comunicação (1), Ciências Sociais e Políticas (1), Educação (2), Estudos de Linguagens e Artes (1), Estudos Interdisciplinares de Gênero (1), Estudos Étnicos Africanos (1), Estudos de Mídias (1), e Sociologia (1). Os subitens 3.1 a 3.2 a seguir tratam a análise das pesquisas realizadas nos dois produtos da atividade científica: dissertações e teses.

\subsection{Análise das pesquisas de mestrado}

Nesta subseção serão analisadas cinco dissertações de mestrado, mediante os critérios definidos no aporte metodológico do trabalho. A ordem de análise dos trabalhos foi pautada por similaridade dos temas.

A primeira dissertação escolhida como vitrine de abertura das análises foi o estudo da pesquisadora Kelly Cristina da Silva (2017). O estudo apresenta uma análise 
netnográfica, dos sujeitos da pesquisa: mulheres negras de 15 a 29 anos, educandas da EJA, e que frequentam grupos da rede social Facebook. Em conclusão, o trabalho mostra que há um processo de apropriação do conhecimento pelas interações em rede e ainda aponta várias questões para o percurso dessas interações, sendo uma delas um recorte temporal cumulativo emancipatório que possibilita deslocamentos identitários e quebras de paradigma.

A segunda dissertação selecionada da autoria de Dailza Araújo Lopes (2017). Nela, a pesquisadora contextualiza o ciberativismo em rede sob a liderança de mulheres negras presentes em três grupos de coletivo negro do Facebook, direcionada à cidade de Salvador, na (Bahia). O trabalho considerou uma reconstrução discursiva em torno do cabelo crespo pela desconstrução de padrões estéticos. Os estudos apontaram que as redes sociais são um campo que promove mobilização política e social para além das organizações tradicionais.

A terceira análise se ocupa da dissertação da pesquisadora Gessica Castro da Silva Viana (2019), O trabalho propõe um estudo comparativo de abordagem qualitativa e descritiva sobre as produções de Youtubers mulheres (negras e não negras), em quatro canais da plataforma. Em análise às falas das youtubers negras, a autora afirma que os dados apontam para uma justificativa de que, não sendo essas mulheres compreendidas no contexto (de gênero/de raça ou genérico/racial), a posição de exceção é reiterada enquanto a de pluralidade em contextos de múltiplas dimensões é (desprezada/desqualificada).

$\mathrm{Na}$ quarta análise, discorre-se sobre o trabalho da pesquisadora Claudia Maria Pinheiro da Boa Morte (2017). Neste estudo, a proposta central investigou a imagem constituída socialmente em torno do cabelo crespo e incluso as produções e reproduções discursivas direcionadas à estética negra em comunidades do Facebook. $\mathrm{O}$ trabalho conclui que a rede social Facebook possui caráter de inovação pela forma de interação observada. As comunidades revelaram antagonismos entre os discursos, a exemplo das ideias de beleza permeadas por questões históricas e sociais.

Por fim, a análise da dissertação de Suzielen Taiane das Graças (2018). A pesquisa retrata o ativismo de mulheres negras em redes sociais e propõe um mapeamento no YouTube, Facebook e Blogs para observar o acesso a esses espaços e estabelecer uma relação de sentido na parceria entre essas mulheres e suas histórias de vida. O ponto central da leitura interseccional dos dados destaca-se pela superação da lógica colonial. Outro aspecto evidenciado nos relatos foi o resgate de saberes ancestrais para a formação de interfaces de novas epistemologias.

\subsection{Análise das pesquisas de doutorado}

Nesta subseção serão analisadas quatro teses de doutorado consoante os critérios expostos nas subseções precedentes; havendo, no entanto, diferença quanto à atenção a ser dada à metodologia e finalidade. A ordem dos trabalhos analisados segue o critério de temas por similaridades.

A primeira tese selecionada contextualiza o trabalho da pesquisadora Janine de Kássia Rocha Bargas (2018). Ainda que não direcionada ao gênero negro, esta pesquisa foi selecionada por ter uma seção específica tratando a participação de mulheres negras quilombolas em redes. A base teórica é fundamentada em linhas do pensamento feminista. $\mathrm{O}$ trabalho propõe uma análise de apropriações das mídias digitais como mecanismo de luta territorial, envolvendo o Facebook e Whatsapp como campo de coleta de dados, mediante observação das interações on-line. A pesquisa demonstrou 
que a participação dessas mulheres em rede social promove a quebra do silêncio sobre os modos de subornação que as levam a formas organizativas de luta, como também as regras de pertencimento reveladas nas interações on-line, ao que a autora chamou de "terrenos fundamentais" para novas dimensões de luta dos quilombolas do Pará, pelos seus territórios em permanente atualização e reordenamento.

De Júlia Silveira Araújo (2018) é a segunda tese analisada. Assim como a anterior, essa pesquisa não está diretamente direcionada ao gênero negro. A autora busca compreender as articulações ativistas das campanhas feministas indexadas por hashtags nas redes sociais, considerando os seguintes tópicos de análise: iniciativas em si, as narrativas íntimas e os desdobramentos dessas mobilizações articuladas pela pauta da igualdade de gênero. A pesquisa concluiu que há uma produção de discursos públicos sobre a vida pessoal como bandeira de luta, e que grupos marginalizados encontram abertura e poder de discurso nas redes sociais pesquisadas.

A terceira tese analisada $d a$ pesquisadora Maria Érica Santana de Souza (2017). A análise se ocupou de dois aspectos: uso das redes sociais para fins de militância feminista e identificação dos meios, interfaces e formas de organização das manifestações de junho de 2013, em Aracajú. Nas considerações da autora, as redes sociais formam um espaço de arena pública estabelecido pela ampliação vozes que reivindicam seu lugar de fala na sociedade, militância auto-organizadas e participação política ativa das mulheres, legitimidade em pautas consideradas emancipatórias e geradoras de autonomia, autogestão e novas estratégias de luta.

A quarta tese analisada é de autoria da pesquisadora Tatiana Santos P (2019). O estudo investiga as narrativas e processos formativos decoloniais do ativismo de mulheres negras na rede social YouTube com o objetivo de compreender as pautas de reivindicações nos canais protagonizados por mulheres negras. $\mathrm{O}$ estudo apontou as situações etnográficas narradas: apropriações midiáticas, tensões com mecanismos comerciais, postura e articulações com o mercado de consumo e relação de consumo de mulheres negras.

\section{Apontamentos finais}

Os trabalhos selecionados neste estudo apontaram dados que qualificam o rompimento de estruturas e o surgimento de novos fenômenos a serem descortinados e aprofundados pelo viés da pesquisa. Em síntese, os discursos e modos de representações comportamentais sedimentam padrões sociais que estruturam o pensamento e o comportamento de toda uma nação (exemplo do Brasil e do seu triste histórico de racismo e sexismo), dois temas muito bem tratados nos nove trabalhos analisados. Como trabalhos futuros, a pesquisa será estendida para o campo dos artigos científicos. Ainda, percebeu-se que a busca pode ser ampliada para o campo das mídias sociais.

Dessa forma, faz-se necessário fortalecer essas bases metodológicas para que, cada vez mais, o ciberespaço seja explorado e contribua com a interpretação de fenômenos que ajudem as Ciências Sociais e outras áreas que fazem ciência a responder e solucionar questões sociais. Entendendo melhor todo esse contexto, também é possível produzir tecnologias que mitiguem problemas sociais como o racismo.

\section{Agradecimentos}

Essa pesquisa teve apoio da Coordenação de Aperfeiçoamento de Pessoal de Nível Superior (CAPES) - Bolsa Demanda Social/Doutorado, e do Conselho Nacional de Desenvolvimento Científico e Tecnológico (CNPq) - Bolsa Produtividade em Pesquisa. 


\section{Referências}

Araújo, J. S. (2018). Minha rede, Minhas Regras: hashtags, mobilização de mulheres e publicação de narrativas íntimas na internet. 2018. Tese Doutorado em Comunicação, Universidade Federal Fluminense, Rio de Janeiro.

Bargas, K. R. (2018) Quilombolas do Pará e Mídias digitais: sociabilidade, conflito e mobilização online nas lutas por reconhecimento. Tese Doutorado em Comunicação Social, Universidade Federal de Minas Gerais, Uberlândia.

Boamorte, C.M.P. (2017). (Re)Assumindo a Raiz: a discursivização sobre a mulher negra a partir da noção de cabelos crespos, presente nas comunidades do Facebook. Dissertação Mestrado em Linguagem e Artes, Universidade Estadual da Feira de Santana.

Cruz, D. A. C. S.; Brandão, C.W. G. S. (2018) Representação da mulher negra na cultura digital: combate ao preconceito na rede. In: XX Redor, Encontro da Rede Feminista do Norte e Nordeste de Estudos e Pesquisas sobre Mulher e Relações de Gênero, 201. Anais. Salvador UFBA.

da Silva, K. C. (2017). Os letramentos de empoderamento feminino negro: a educação de jovens e adultos e os aprendizados na rede social Facebook. DissertaçãoMestrado em Educação, Universidade Federal de Minas Gerais, Uberlândia.

Graças, S.T. (2018) Resistência ativismo e articulação de mulheres negras através de redes sociais. Dissertação Mestrado em Relações Internacionais e Ciência PolíticaUniversidade Federal da integração Latino-Americana. Foz do Iguaçu.

Lobo, M. M.; Ribeiro K.; Maciel, C. (2020). Black Women in Computing and Technology: Identity affirmation and Resistance. CLEI Electron. J. 22(2) (2020).

Lopes, D. A. (2017) Ciberativismo como estratégia política: um estudo sobre mulheres negras, crespas e cacheadas no Facebook. 2017. Dissertação-Mestrado em Estudos Étnicos Africanos, Universidade Federal da Bahia. Salvador.

Paz, T. S. (2019). Ativismo em rede e processos formativos decoloniais articulados por mulheres negras no Youtube. Tese- Doutorado em Educação, Universidade Federal do Ceará, Fortaleza.

Santana, M. É. (2017) Formas de militância feminista em cenário de auto-organização de ciberativismo no Brasil contemporâneo: tendências atuais a partir do caso de Aracajú/SE. 2017. Tese - Doutorado em Sociologia, Universidade Federal de Sergipe, São Cristóvão, 2017.

Souza. N. (1983). Tornar-se negro ou as vicissitudes da identidade do negro brasileiro em ascensão social. 2. ed. Rio de Janeiro: GRAAL.

Therrien, S. M; Therrien J. (2004) Trabalhos Científicos e o Estado da Questão: reflexões teóricas metodológicas. Revista Estudos em Avaliação Educacional, Fortaleza v.15, n. 30, jul./dez.

Viana, G. C. da S. (2019) Ciberfeminismo e a (in) visibilidade da mulher negra. Dissertação Mestrado em Estudos de Mídias, Universidade Federal do Rio Grande do Norte, Natal, 2019. 